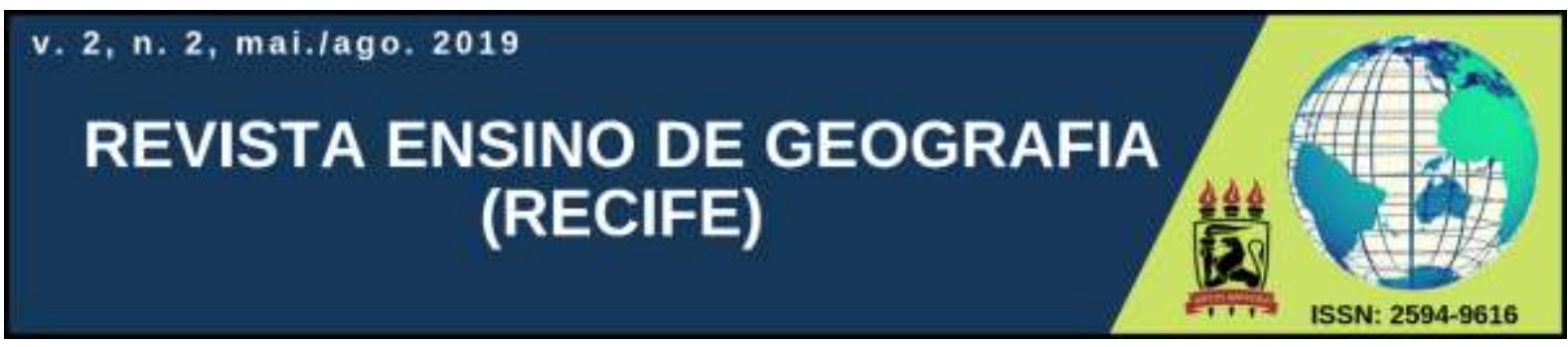

\title{
REFLEXÕES SOBRE UMA OFICINA DE COSMOGRAFIA E DE ORIENTAÇÃO GEOGRÁFICA: TECENDO RELATOS DE PRÁTICA SOBRE O PIBID GEOGRAFIA UFSM $2018^{1}$
}

\author{
Fabiano Dal Ongaro \\ Graduando em Geografia pela UFSM e bolsista PIBID Geografia UFSM \\ E-mail: fabiano.on.ufsm@gmail.com \\ ORCID iD: https://orcid.org/0000-0002-1884-2340 \\ Maicon Douglas Herber \\ Graduando em Geografia pela UFSM e bolsista PIBID Geografia UFSM \\ E-mail: maicon.herber@gmail.com \\ ORCID iD: https://orcid.org/0000-0002-1884-2340
}

Natália Lampert Batista

Graduada em Geografia (Licenciatura) pelo Centro Universitário Franciscano. Mestra, Doutora e Pós-doutoranda em Geografia pelo PPGGeo/UFSM. Foi Supervisora do PIBID Geografia UFSM, na Escola Municipal de Ensino Fundamental Junto ao CAIC Luizinho de Grandi, em 2018 e 2019.

E-mail:natilbatista3@gmail.com

ORCID iD: https://orcid.org/0000-0002-1884-2340

Artigo recebido em 04/06/2019 e aceito em 21/09/2019

\begin{abstract}
RESUMO
Pensar a relação entre a cosmografia e a orientação geográfica é fundamental para o desenvolvimento de noções sobre a localização espacial nos estudantes da educação básica. Assim, os bolsistas do Programa Institucional de Bolsas de Iniciação a Docência (PIBID), subprojeto Geografia, da Universidade Federal de Santa Maria (UFSM), pensaram a presente prática pedagógica para ser desenvolvida em suas turmas de atuação no segundo semestre de 2018. Com base nisso, o presente trabalho objetiva apresentar e discutir uma oficina pedagógica sobre cosmografia e orientação geográfica realizada pelos bolsistas PIBID Geografia da UFSM na Escola Municipal de Ensino Fundamental Junto ao CAIC Luizinho de Grandi, localizada na região administrativa sul de Santa Maria/RS. A oficina foi realizada com duas turmas de $7^{\circ}$ ano. Para sua realização, os bolsistas, primeiramente, observaram duas aulas em cada turma e conheceram brevemente o contexto dos estudantes. Neste momento de observação, realizaram a sondagem dos temas de interesses dos alunos para definirem qual assunto poderiam abordar. Após, desenvolveram um plano de aula para a oficina e organizaram os materiais necessários para a realização das práticas. Por fim, aplicaram as atividades e sistematizaram esse texto refletindo
\end{abstract}

\footnotetext{
${ }^{1}$ Agradecemos a Coordenação de Aperfeiçoamento de Pessoal de Nível Superior (CAPES) pelas bolsas de Iniciação à Docência e de Supervisão concebidas aos autores do presente artigo e ao coordenador do PIBID Geografia UFSM 2018, Prof. Dr. Adriano Severo Figueró, pelas orientações referentes ao Programa e pelos excelentes debates nas reuniões do Projeto.
} 
sobre a proposta pedagógica empreendida. A oficina motivou os estudantes quanto à retomada das temáticas que já haviam sido trabalhadas no ano anterior e auxiliou na construção e no avivamento dos conhecimentos geográficos sobre a temática.

Palavras chave: Oficina Pedagógica. Ensino Fundamental. Proposta Didática.

\title{
REFLECTIONS ON A GEOGRAPHICAL COSMOGRAPHY AND GUIDANCE WORKSHOP: WRITING REPORTS OF PIBID GEOGRAPHY PRACTICE UFSM 2018
}

\begin{abstract}
Thinking about the relationship between cosmography and geographical orientation is fundamental for the development of notions about spatial location in students of basic education. Thus, the scholarship holders of the Programa Institucional de Bolsas de Iniciação à Docência (PIBID), Geography subproject, of the Universidade Federal de Santa Maria (UFSM), thought of the present pedagogical practice to be developed in their classes in the second semester of 2018. With Based on this, the present work aims to present and discuss a pedagogical workshop on cosmography and geographic orientation conducted by the PIBID UFSM Geography fellows at Escola Municipal de Ensino Fundamental Junto ao CAIC Luizinho de Grandi, located in the southern administrative region of Santa Maria/RS. The workshop was held with two 7th grade classes. For the workshop, the scholarship students first observed two classes in each class and briefly learned about the students' context. At this time of observation, they conducted a survey of topics of interest of students to define which subject could address. Afterwards, they developed a lesson plan for the workshop and organized the materials needed to perform the practices. Finally, they applied the activities and systematized this text reflecting on the pedagogical proposal undertaken. The workshop motivated the students when the resumption of the themes that had already been worked on the previous year and helped in the construction and revival of the geographic knowledge about the theme.
\end{abstract}

Keywords: Pedagogical Workshop. Elementary School. Didactic Proposal.

\section{INTRODUÇÃO}

Desde a pré-história, os seres humanos sempre apresentaram a necessidade de estabelecer a sua localização na superfície terrestre. Para isso, começaram a observar a natureza e, em especial, o céu para entender como se orientarem e se localizarem no espaço. Desta observação sistemática e constante nasceram inúmeras técnicas e metodologia para localização e para a orientação espacial que se perpetuaram, chegando até a contemporaneidade. A orientação a partir dos astros, como o Sol, a Lua e as estrelas, foi fundamental para desenvolver as direções da rosa-dos-ventos, por exemplo, e, consequentemente, aperfeiçoar das noções de localização (BATISTA et al, 2014). Tal fato que faz com que a cosmografia tenha reflexo na cartografia escolar e no ensino de Geografia como um todo.

Logo, a compreensão dos astros colabora significativamente com o desenvolvimento de noções sobre a organização do Sistema Solar e, por conseguinte, de localização conduzindo então à necessidade de estudar elementos da cosmografia aliados a orientação 
geográfica. Por isso, sempre que se fala em localização e orientação, não se pode perder de vista os elementos inerentes à cosmografia geográfica e ao estudo dos corpos celeste. Os movimentos da Terra, em torno de si e do Sol, os elementos astronômicos que têm influenciam no Planeta, entre outros elementos, são essenciais à discussão geográfica e, consequentemente, para estabelecer as bases de alguns temas associados à cartografia escolar ${ }^{2}$.

O termo cosmografia apresenta uma série de significados, mas neste estudo adotamos como a ciência das relações entre Geografia e o estudo dos astros ou ainda descrição dos corpos celestes do Universo (SOBREIRA, 2005). Além disso, pode ser definida como:

[...] é um campo de estudos da Geografia, cujo conjunto de conhecimentos e habilidades é predominantemente escolar. Estuda a interface entre os conhecimentos terrestres e os celestes e lhes atribui significância geográfica. Analisa as relações humanas e naturais com o espaço sideral e suas consequências para a sociedade e a natureza e, portanto, para a organização do espaço. (SOBREIRA, 2012, p. 162).

Apesar diversas definições para o termo e estudos sobre ele, porém há poucos materiais que abordam o tema efetivamente no ensino de Geografia. Sobreira (2005 e 2012) e Rodrigues (2019) são alguns dos autores que se dedicam ao tema na contemporaneidade com foco no ensino, por isso práticas com essa temática se tornam tão necessárias e relevantes nas aulas de Geografia.

Em sua tese, Sobreira (2005) reforça as diferentes cosmovisões sobre a Terra e como os estudos cosmográficos colaboram com a astronomia, astronáutica, cartografia, geografia, entre outras. O autor ainda reforça que o termo foi utilizado pela primeira vez por Ptolomeu, no século II d. C., como título de uma obra de cunho geográfico e cartográfico, tornando evidente a relação entre os estudos dos astros e a localização e orientação. De acordo com Rodrigues (2019):

A Cosmografia Geográfica ou Cosmogeografia (termo utilizado por alguns autores) é um ramo de estudo da Geografia Escolar responsável pela descrição dos elementos que compõem o cosmos e das dinâmicas de seus agentes que causam efeitos intervenientes no planeta Terra, interferências, essas, que podem ser no campo físico ou sociocultural. (RODRIGUES, 2019, p. 55).

\footnotetext{
${ }^{2} \mathrm{~A}$ cartografia escolar é uma área muito ampla que envolve a articulação entre ensino, geografia e cartografia. Todavia, interfaces essenciais para o desenvolvimento de noções cartográficas como a orientação são contempladas nessa oficina.
} 
Por outro lado, segundo Sobreira (2005), atualmente o termo "cosmografia" está em desuso, mas deve ser retomado, especialmente, neste início de século XXI como uma forma de auxiliar o ensino de Geografia, de astronomia e de cartografia, sobretudo, no que tange a orientação e localização geográfica e a interpretação do cosmos. De acordo com o autor, o espaço cósmico vem sendo apropriado pelo ser humano e isso reforça a necessidade de compreendê-lo e retomá-lo como foco de estudo. Por outro lado, tais temáticas motivam o imaginário dos estudantes da educação básica e os fazem "viajar" na busca de novos conhecimentos, empoderando a própria Geografia enquanto disciplina escolar, fato que justifica a realização de oficinas pedagógicas sobre o assunto.

Assim:

A Cosmografia Geográfica é um campo de conhecimentos vasto, e assim como as disciplinas comuns aos currículos pode ser estudada tanto em sua análise educacional, percebendo como os alunos compreendem o conceito de espaço extraterrestre por meio de projetos de ensino e de extensão, como em seus conteúdos específicos, na prática laboratorial e nas observações do céu e seus fenômenos (RODRIGUES, 2019, p. 56).

A cosmografia, neste sentido, acaba colaborando também com a orientação geográfica, pois as direções são articuladas com os movimetnos dos astros, ou seja, como coloca Passini (2012):

É preciso que o aluno relacione a direção Leste-Oeste ao movimento de rotação da Terra. Ele deve entender que o Sol "surge" a Leste porque a Terra gira de Oeste para Leste [...]. O aluno deve entender que a trajetória descrita pelo Sol no céu durante o dia é resultante do movimento da Terra e não do Sol. (PASSINI, 2012, p. 97).

Segundo Dambros (2014), a orientação deve ser desenvolvida a partir do reconhecimento dos pontos cardeais, apoiando-se na observação e na compreensão do movimento aparente do Sol e isso liga diretamente os estudos cosmográficos à cartografia escolar, à orientação geográfica e ao desenvolvimento de habilidades e competências no que concerne a orientação e a localização geográfica. Em outras palavras, Simielli (1999) aponta que a alfabetização cartográfica envolve algumas noções básicas que podem estar associadas à localização e à orientação pelos astros.

Já Teixeira e Cartrogiovanni (2014) mencionam que:

Atividades que envolvem o corpo, mais precisamente a noção corporal de direita e esquerda ou hemisferização corporal, desenvolvem domínios necessários para a 
leitura de mapas. [...] $\mathrm{Na}$ orientação, o aluno precisa da lateralidade para construir referências aos astros, como o Sol, por exemplo, e relacionar o sentido (Norte, Sul, Leste e Oeste) à sua direita ou esquerda. (TEIXEIRA; CASTROGIOVANNI, 2014, não paginado).

Partindo dessas premissas, o presente trabalho objetiva apresentar e discutir uma oficina pedagógica sobre cosmografia e orientação geográfica realizada pelos bolsistas do Programa Institucional de Bolsas de Iniciação à Docência (PIBID) Geografia da Universidade Federal de Santa Maria (UFSM), na EMEF Junto ao CAIC Luizinho de Grandi em 2018.

\section{Caminho metodológico para o artigo}

A presente proposta de trabalho se originou da inserção dos bolsistas PIBID Geografia UFSM nas aulas de Geografia da Escola Municipal de Ensino Fundamental Junto ao CAIC Luizinho de Grandi, localizada na região administrativa sul de Santa Maria/RS (Figura 1). As atividades do PIBID no ano de 2018 enfocaram, principalmente, a monitoria nas aulas dos estudantes da educação básica e a realização de oficinas pedagógicas de temática livre nas escolas vinculadas ao programa. Essa metodologia foi adotada, pois a maioria dos estudantes vinculados à bolsa se encontrava no segundo semenstre da graduação e, portanto, vivenciavam a primeira experiência docente. Assim, para as reflexões derivadas dessas vivências são oriundas da primeira atividade em ambiente escolar desenvolvidas pelos graduandos e, por isso, conta com uma abordagem mais empírica e formatada como relato de expriência. 


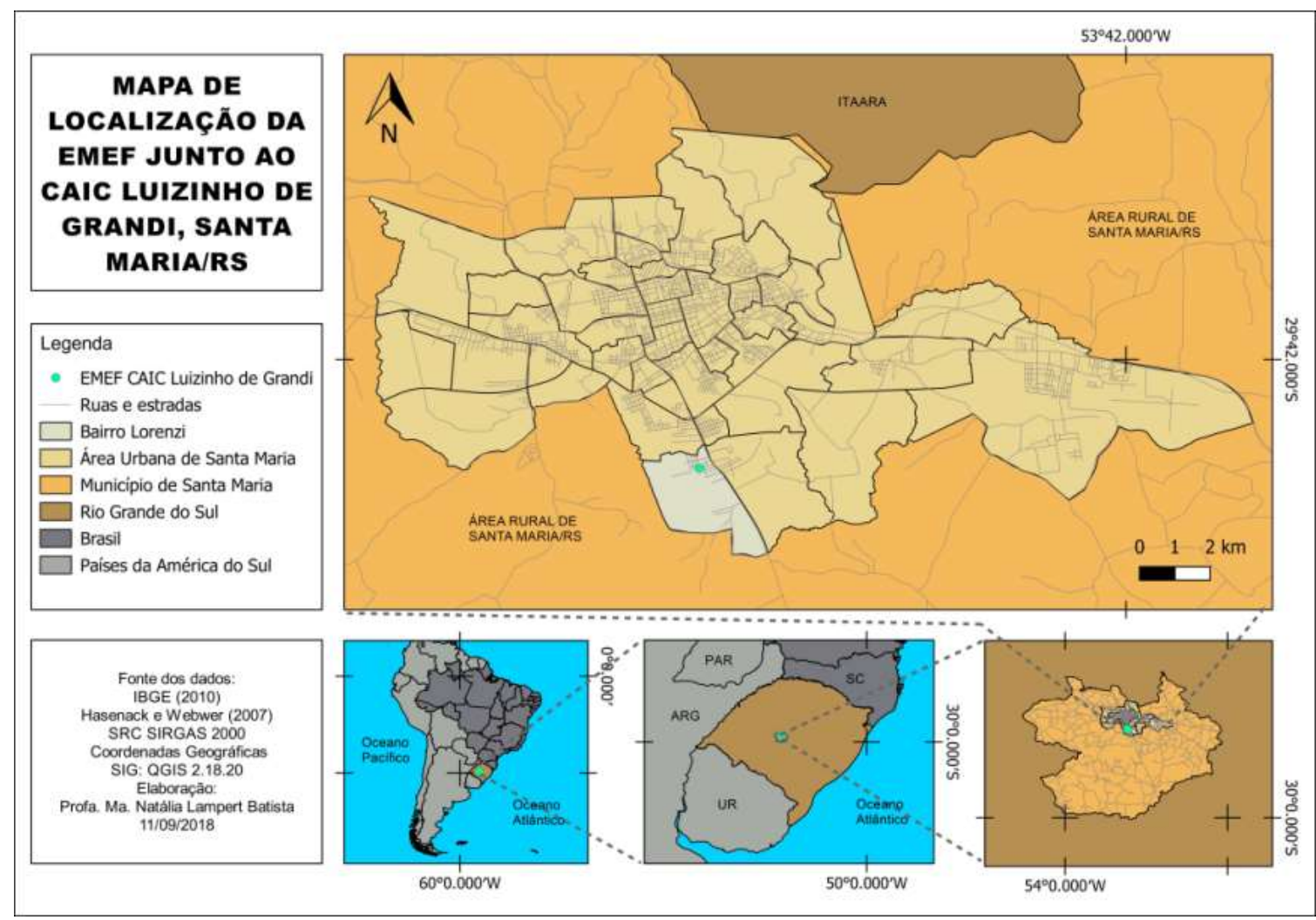

Figura 1 - Mapa de localização da EMEF Junto ao CAIC Luizinho de Grandi. Fonte: Elaboração própria, 2018.

Ressalta-se que o PIBID tem como objetivo "incentivar a formação de docentes para a educação básica a nível superior, elevar a qualidade da formação inicial de professores nos cursos de licenciatura, promovendo a integração entre educação superior e educação básica e a melhoria de qualidade da educação pública brasileira" (BRASIL, 2018, p. 01). A partir do programa, os graduandos de licenciaturas desenvolvem atividades pedagógicas em escolas da rede pública conveniadas ao programa, sob a supervisão de um professor da educação básica e de um coordenador institucional da educação superior. O programa contribui para a articulação entre teoria e prática necessárias à formação dos futuros docentes e promove uma co-formação (inicial e continuada) de professores de todos os níveis e modalidades de ensino.

A oficina aqui relatada foi realizada com duas turmas de $7^{\circ}$ ano, cujos alunos estavam matriculados em 2018, e contou com aproximadamente cinquenta participantes. Sua aplicação totalizou quatro períodos de cinquenta e cinco minutos da disciplina de Geografia.

Para a realização das práticas, os bolsistas, primeiramente, observaram duas aulas em cada turma e conheceram brevemente o contexto dos estudantes. Neste momento de observação, realizaram a sondagem dos temas de interesses dos alunos para definirem qual assunto poderiam abordar. Essa sondagem foi realizada por meio de conversas informais com 
os estudantes, pois a intenção era aproximar os estudantes dos bolsistas PIBID para que, a partir disso, se estabelecessem relações de confiança e aprendizagem mútua.

Após esse primeiro contato com os alunos da escola, os bolsistas desenvolveram um plano de aula para a oficina e organizaram os materiais necessários para a realização das práticas. Por fim, aplicaram as atividades e sistematizaram esse texto refletindo sobre a proposta pedagógica empreendida. Por se tratar de uma primeira inserção na escola e pelo fato do texto produzido se caracterizar como um relato de experiência, optou-se por não fazer coletas de dados formais para a avaliação da proposta ou mesmo da "aprendizagem" dos estudantes. Preferiu-se trabalhar com relatos de impressões baseados nas conversas e nas vivências com os estudantes. Além disso, a aprendizagem desencadeada pela proposta foi mútua, alunos da escola e graduandos puderam fortalecer vínculos com a temática tratada e, assim, exercitar os conhecimentos geográficos como prática docente.

Ressalta-se, que os temas cosmografia e cartografia compõem o currículo do $6^{\circ}$ ano do ensino fundamental em Santa Maria/RS, todavia, os estudantes da escola, mesmo no $7^{\circ}$ ano manifestaram curiosidade em retomar tal temática. Além disso, a atividade compreendeu a primeira inserção dos bolsistas PIBID Geografia UFSM em espaço escolar como estudantes de licenciatura e futuros professores e, portanto, optou-se por trabalhar um tema que os mesmo apresentam maior autonomia para desenvolver em sala de aula.

\section{Pensando a prática pedagógica}

A prática pedagógica desenvolvida na escola foi pensada a partir de vivências e leituras de estudantes de segundo semestre de graduação, sob a supervisão da professora regente da turma. Para a realização da oficina de cosmografia e orientação geográfica, primeiramente, os bolsistas PIBID Geografia UFSM realizaram observações nas aulas de Geografia. Nessas observações os graduandos deveriam observar como eram os alunos, quais suas afinidades e preferências com relação aos conteúdos geográficos, que estratégias metodológicas eram mais interessantes aos grupos de alunos para os quais eles iriam ministrar suas oficinas. Essas observações se deram de forma empírica e as reflexões sobre elas se basearam nas vivências dos graduandos em sala de aula.

Além disso, durante essas observações, realizaram-se sondagens com os alunos, perguntando-lhes sobre quais os assuntos eles tinham mais curiosidade das aulas de 
Geografia, quais conteúdos eles gostariam que fossem retomados ou abordados pela primeira vez, que temas eram de interesse coletivo, independente que qual série isso tenham sido trabalhados. Como resultada da sondagem, observou-se que os alunos possuíam grande afinidade com as temáticas da cosmografia e da orientação geográfica e apresentavam uma série de questões a serem debatidas sobre esses temas. Entre as dúvidas levantadas estavam: “Como podemos nos localizar observando os astros?", "Qual a composição dos Planetas?”, “Como os povos antigos sabiam onde estavam?”, "Quais são os principais corpos celestes existentes?", “O que é um buraco negro e uma estrala anã? O sol é uma estrela anã??, entre outras questões. A partir dessas observações e das dúvidas que emergiram das sondagens iniciais propôs-se a oficina aqui relatada. A Figura 2 apresenta uma parte dos estudantes envolvidos na proposta com os bolsistas PIBID Geografia UFSM na segunda aula de observação.

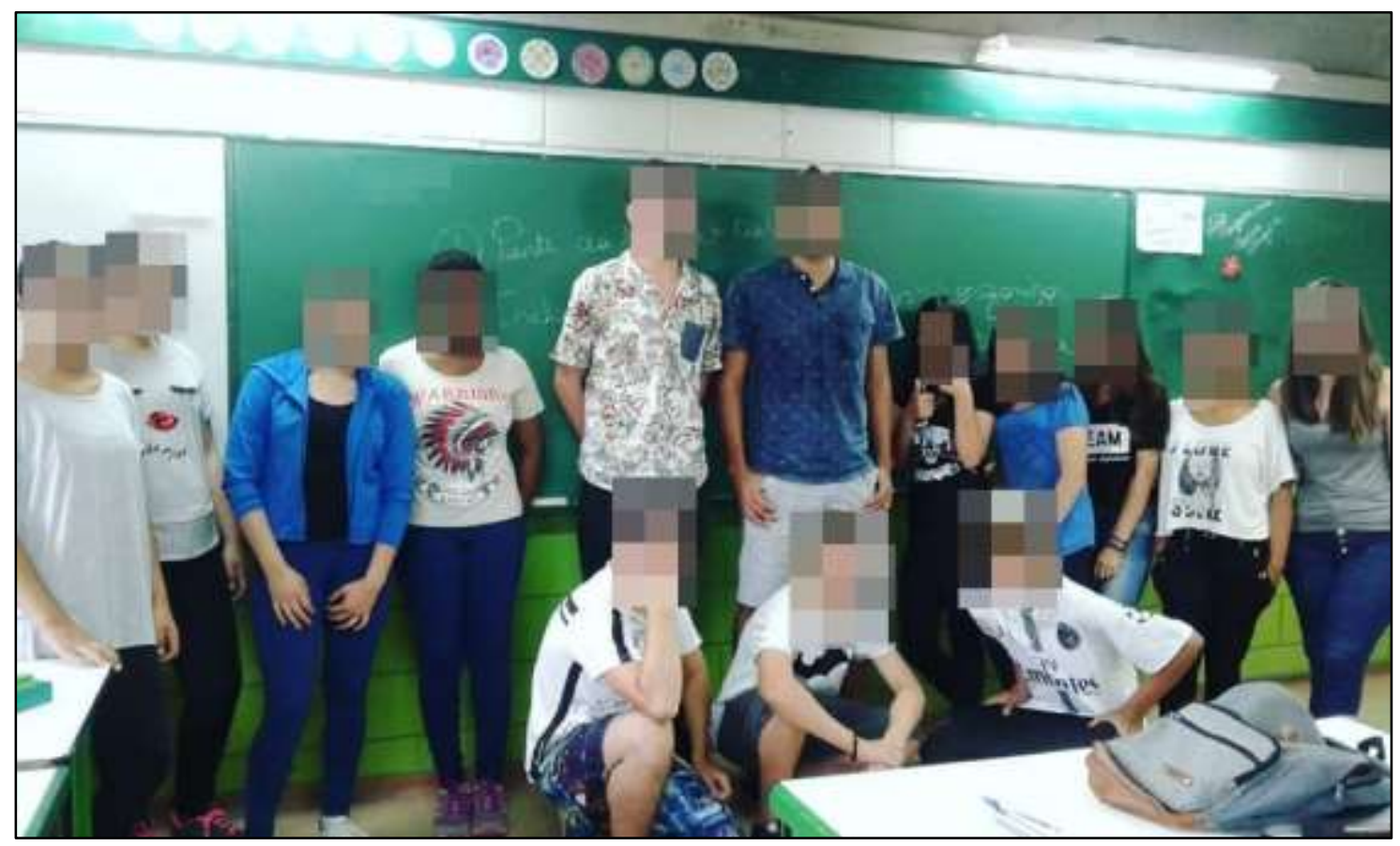

Figura 2 - Bolsistas PIBID Geografia UFSM e alguns alunos envolvidos nas práticas realizadas na Escola Municipal de Ensino Fundamental Junto ao CAIC Luizinho de Grandi após uma das aulas de observação. Fonte: acervo pessoal dos autores, 2018.

Após, definir o tema, os bolsistas, juntamente com a professora supervisora, realizaram leituras sobre a temática a ser abordada e confeccionaram um plano de aula contendo os objetivos, a metodologia e os materiais necessários para a realização da oficina. Observou-se durante essa pesquisa preliminar que há poucas referências voltadas ao ensino de 
cosmografia na Geografia. Todavia, há diversos materiais que podem ser utilizados desde que se faça uma transposição didática adequada sobre o tema.

Depois de organizar todo esse material, agendou-se quatro períodos para a realização das práticas. Cada turma participou dos momentos da oficina no seu horário de aula. Assim, uma das turmas realizou a oficina em duas manhãs (dois períodos por turno de aulas) e a outra a realizou em quatro manhãs (um período por turno). A organização da prática, de acordo com os horários de aula pré-estabelecidos, resultou em diferenças nos resultados. Notou-se que as turmas que em os períodos de aula foram juntos a oficina fluiu de forma mais tranquila, pois havia mais tempo para as explicações e debate, permitindo, assim, uma maior interação entre os participantes. Já as aulas em duas manhãs diferentes acabaram sendo um pouco menos produtivas, pois os estudantes acabavam não retomando seus questionamentos anteriores e, quando os bolsistas o faziam, às vezes, o interesse já mais estava mais tão evidente. Já haviam novas questões levantadas e por serem realizadas.

Durante a oficina, em primeiro momento, explicou-se aos alunos a dinâmica das atividades para que eles compreendessem todo o processo que seria desenvolvido, bem como para que dar-lhes uma visão geral de todas as atividades que necessitariam desenvolver. Após, começou-se a trabalhar uma revisão sobre os conhecimentos referentes à cosmografia geográfica relacionando-os com a orientação. Relembraram-se com as atividades sobre os astros e corpos celestes e a sobre a composição e a organização do Sistema Solar, movimentos da Terra e curiosidades astronômicas. Na sequência, como atividade prática, desenvolveu-se uma atividade de estamparia de camisetas com motivo cosmográficos (Figura 3). Toda produção de materiais foi despertando a curiosidade dos alunos que passaram a levantar questões e a debates durante a produção das estamparias. Eles relacionavam o conhecimento teórico com os "porquês" dos elementos que iriam adereçar suas camisetas. Além dos elementos associados à cosmografia fez-se também uma estampa da logomarca do PIBID para associar a produção ao Projeto. 


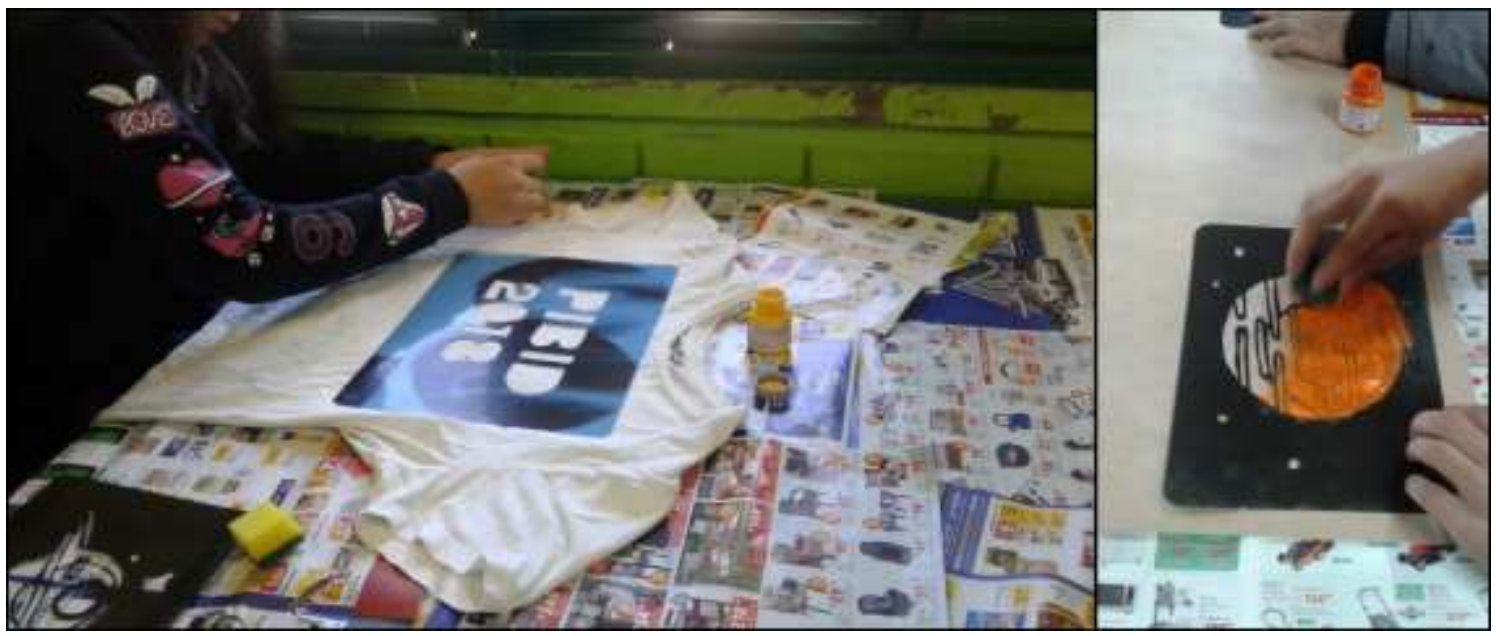

Figura 3 - Momentos da atividade de estamparia: à esquerda, observamos o molde utilizado para a logomarca do PIBID sendo fixado na camiseta do estudante e, à direita, destaca-se o processo de estampa com tinta de tecido. No caso, o estudante está utilizando o molde da lua para compor a estampa.

Fonte: acervo pessoal dos autores, 2018.

Os bolsistas distribuíram as bases para as estampas em camisetas (que foram trazidas pelos estudantes e pelos próprios bolsistas PIBID), confeccionadas com papéis de radiografia reciclados, tintas de tecido e esponjas para a realização da pintura dos motivos escolhidos pelo os alunos. Cada estudante estampou sua camiseta ou as camisetas de colegas como elementos do Sistema Solar. Durante a confecção das estampas foram problematizados temas referentes à composição dos Planetas, características físicas de cada diferente corpo celeste, localização dos elementos no Sistema Solar, bem como se destacou elementos que auxiliam na orientação geográfica.

Essa estratégia adotada tornou a aula um espaço de troca e conversas sobre o tema em análise. A estrutura organizada fez com que ocorresse a horizontalização das relações entre docentes (graduandos) e estudantes, fazendo com que as teorias dos alunos e questionamentos emergissem naturalmente, bem como potencializou o exercício da criatividade, pois os alunos puderam se manifestar e se expressar nas camisetas que confeccionaram durante a prática.

Desta maneira, a Geografia escolar deve estar alicerçada em saberes teóricos, em saberes práticos e em saberes didáticos, pois é imprescindível que o professor conheça seu objeto de estudo e ensino, bem como que ele saiba relacionar tudo isso com as áreas de interesse dos educandos e com qual o melhor caminho para fazer o estudante compreenda os conceitos e teorias que estão sendo abordados. A horizontalização das relações e as conversas mediadas pela prática da estamparia tornaram a atividade significativa, fazendo com que os alunos se motivassem e trocassem informações sobre o tema de forma aberta e espontânea. Desse modo, 
O ensino de geografia na educação básica deverá ter como objetivo central a formação cultural do aluno pelos conhecimentos que constituem essa ciência. Tais conhecimentos deverão ser articulados, postos em interação, pois assim se favorecerá o educando com o desenvolvimento do raciocínio espacial. (ASCENÇÃO; VALADÃO, 2013, p.61).

Após a atividade de estamparias, retomou-se a questão da orientação pelos astros e por objeto com mais ênfase. Discutiu-se com os estudantes como eles podem utilizar elementos do cosmos para se posicionarem no espaço retomando a abordagem realizada durante a oficina de estamparias. Apesar de parecer uma relação evidente para quem estuda Geografia, os estudantes ainda apresentavam uma leitura frágil sobre como saber sobre os astros poderiam ser utilizada para localização espacial. Assim, foi realizada essa associação e explicando os movimentos da Terra e o posicionamento dos astros e, consequentemente, como se localizar com eles.

Portanto, promover a associação entre os dois temas de interesses dos estudantes, cosmografia e orientação geográfica, que tem vínculo direto, mas que não é tão evidente aos alunos da educação básica, contribui significativamente para romper com práticas pedagógicas que não estão centradas no estudante e, consequentemente, que acabam matando o seu interesse pelo ensino de Geografia. É preciso cumprir o currículo e as diretrizes educacionais, mas também é preciso instruir os educandos para que consigam fazem uma leitura mais aprofundada dos temas que lhes são pertinentes. Assim, se:

\begin{abstract}
Os conteúdos não são arregimentados a fim de se aclararem questões do vivido (próximo ou distante). Eles (os conteúdos) têm valores em si mesmos e são estudados para que sejam conhecidos per si deixando, assim, vazio de sentido social o ensino naquela disciplina. Encerra-se nessa equação a relação entre a seleção de conhecimentos e a crise por que passa a geografia escolar na atualidade. (ASCENÇÃO; VALADÃO, 2013, p.51).
\end{abstract}

Em próximo momento, realizou-se a construção de uma bússola caseira ${ }^{3}$ com os alunos para destacar a questão dos pontos cardeais, associando-os a orientação pelo sol, e realizou-se uma atividade de caça ao tesouro com dicas relacionadas aos pontos cardeais, a bússola e aos astros estudados anteriormente. Essa atividade foi realizada no pátio da escola e no final os alunos encontravam como "tesouro" chocolates e uma reflexão sobre a importância de estudar e construir conhecimentos, conforme apresentado na Figura 4.

\footnotetext{
${ }^{3}$ Confeccionada com um copo de água, uma agulha imantada, uma tampa de garrafa pet e um imã de geladeira. Após imantar a agulha ela direciona-se ao norte magnético.
} 


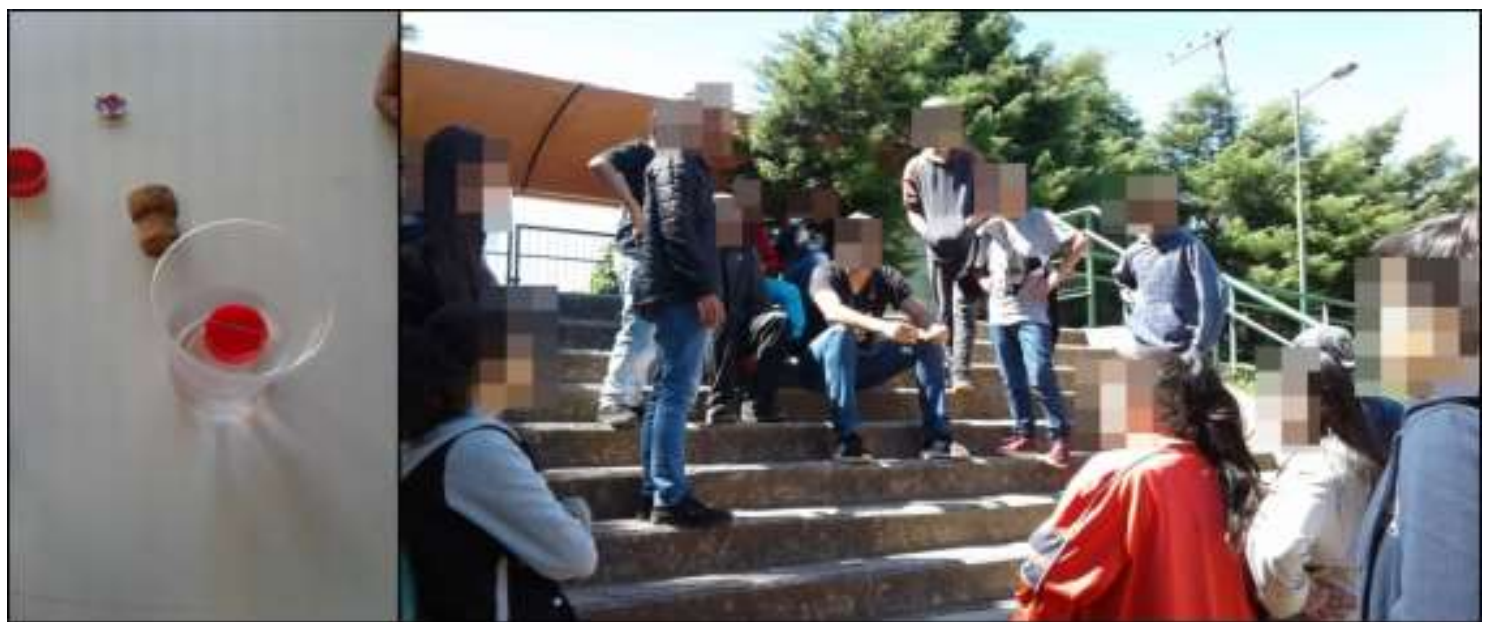

Figura 4 - Bússola construída pelos bolsistas PIBID e alunos e momento final da atividade de orientação e localização.

Fonte: acervo pessoal dos autores, 2018.

Essa atividade serviu para reforçar noções de localização e orientação espacial, bem como para aproximar as duas temáticas foco de interesse dos alunos. Além disso, o desenvolvimento da oficina colaborou com a aproximação teórico-prática nas discussões sobre ensino de Geografia pelos graduandos e bolsista PIBID. Ascenção e Valadão (2013) ressaltam que a formação de professores nem sempre deu conta dessa necessária aproximação:

Genericamente, pode-se afirmar que os cursos de graduação não atuam para ensinar os futuros geógrafos à interpretação de espacialidades. Ensinam-se conhecimentos referentes aos componentes espaciais. Tal lógica é reforçada quando o jovem professor chega à escola básica e se depara com o livro didático e com a rotina didática de outros colegas. (ASCENÇÃO; VALADÃO, 2013, p.50).

Porém, quando o bolsista PIBID já está pensando a sua futura prática no segundo semestre do curso de licenciatura em Geografia e buscando transpor os conhecimentos acadêmicos para o cotidiano da escola e, também, refletir sobre as práticas realizadas na escola como fonte de construção de saberes, rompe-se o ciclo relatado pelas autoras e se passa para uma formação inicial docente mais coerente e com significado para os graduandos. Como contribuições da prática inicial para a formação dos Bolsistas PIBID Geografia UFSM, destaca-se o relato pessoal de acadêmico e Maicon (2018) que aponta que:

Antes mesmo de ingressar na universidade já tinha decidido: queria ser professor. Desde a pré-escola tive professores inspiradores da rede pública de educação que fomentaram em mim esse desejo de ser agente de uma transformação social 
educadora. Encontrei no PIBID e nas oficinas desenvolvidas para além de um contato direto com a docência: encontrei perspectivas que reforçaram esses laços anteriormente criados. É extremamente emocionante ser chamado de professor pela primeira vez; saber que se está construindo uma troca mútua de conhecimentos e trazendo agentes de aprendizado fora do convencional do que se tem em sala de aula cotidianamente. Ser pibidiano é querer uma educação de maior qualidade, com métodos didáticos inspiradores e que se façam ser lembrados (nesse caso, carregados no peito através de estampas) para que o ciclo de inspiração continue e cada vez tenhamos mais ingressantes nas instituições de ensino superior querendo ser aquilo que forma todos nós: professores. (Elaborado para esse artigo).

Já o graduando e bolsista Fabiano (2018) destaca que:

Nesta primeira experiência como pibidiano, estive observando a metodologia, a forma de educar, de convivência, vi também a importância de planejar as aulas. Obtive uma grande alegria em praticar oficinas com os alunos, vê-los atentos as minhas falas, interagindo, buscando e superando cada problema proposto, foi uma coisa incrível. O PIBID me mostrou o "Choque de realidade" conceituado por Lima (2006) como a diferença que há entre o que se aprende na formação inicial e o jeito como isso ocorre, uma vez que a prática é complementar a teoria aprendida na faculdade. Nesse sentido, enfatizo que é de suma importância unir ambas, pois além de preparar o futuro educador, possibilita a felicidade e o orgulho de ver os alunos alcançando os objetivos. (Elaborado para esse artigo).

Desse modo, conforme os relatos apresentados e as práticas desenvolvidas pode-se perceber que a inserção dos bolsistas PIBID Geografia UFSM colaborou tanto com a aprendizagem dos estudantes da educação básica como com a aproximação dos acadêmicos com seu futuro espaço de trabalho, enriquecendo, assim, a formação docente e as proficiencia na abordagem das temáticas cosmografia e orientação geográfica. Essa primeira inserção no espaço escolar possibilitou compreender dinâmicas específicas do cotidiano da escola e evidenciar pontos fundamentais a formação de professores de Geografia, tais como:

(1) na escola se trabalha com pessoas e, por isso, as propostas podem ter resultados surpreendentes de acordo com as expectativas de quem as propõem e de quem as recebe; (2) o planejamento não é algo rígido, ele norteia o processo de ensino, mas, muitas vezes, precisa ser adaptado e adequado em razão das especificidades do espaço em que se desenvolvem as atividades; (3) o processo de se transformar em professor exige a associação teoria-prática; (4) a reflexão constante sobre os processos e de ensino-aprendizagem e sobre as metodologias de ensino qualifica a atuação docente e justifica a necessidade de relatos de experiência como objeto de pesquisas em educação; (5) o acompanhamento de professores mais experientes é essencial para facilitar o trajeto pedagógico dos novos docentes e acadêmicos de licenciatura, pois esses podem orientar as práticas e auxiliar com a insegurança dos docentes em formação; (6) a universidade deve oportunizar vivências nos distintos espaços escolares para os graduandos das licenciaturas porque isso corrobora o estudo das teorias presentes no espaço acadêmico ao mesmo tempo em que 
apresenta a multiplicidade de realidades existentes e nem sempre contempladas pelos textos clássicos do Ensino de Geografia. (BATISTA et al, 2017, p. 383).

Portanto, é possível inferir que o benefício de integrar universidade e escola na prática escolar é de todos os envolvidos: é garantir que os acadêmicos se beneficiem ao participarem ativamente da organização de práticas de ensino e vivenciá-las na vida escolar e é oportunizar aos escolares o contato com novas formas de aprender e vivenciar a aprendizagem colaborativa (BATISTA et al, 2017).

Com relação ao tema abordado, corrobora-se com Rodrigues (2019) que aponta que:

\begin{abstract}
É necessário que o trabalho em sala de aula sobre concepções de mundo se desdobre em escalas variadas, que transborde os limites terrestres, mostrando aos alunos relações intrínsecas existentes entre o cosmos e os dinâmicos presentes no cotidiano humano. Tal trabalho pode ajudar a tornar os alunos leitores mais críticos de mapas e também mais capazes de estabelecer leituras e interpretações críticas por meio das devidas habilidades de compreensão das relações físicas constitutivas da Cosmografia. O pensamento cosmográfico pode contribuir também para fomentar a união entre os povos, pois ao nos darmos conta da grandiosidade do planeta e do universo a que pertencemos, percebemos que nenhuma atividade humana isolada é exclusivamente definidora de nossa natureza, mostrando como somos sensíveis às pequenas mudanças que podem ocorrer de forma aleatória (ou não) no cosmos. (RODRIGUES, 2019, p. 56).
\end{abstract}

A abordagem realizada retomou conhecimentos trabalhados pelos estudantes referentes à organização e à composição do Sistema Solar, associando esse tema a orientação e localização geográfica, evidenciando que a cosmografia geográfica e a cartografia escolar podem convergir para a abordagem de temas comuns e ampliar as concepções de mundo dos estudantes, colaborando com a construção de conhecimentos socialmente úteis e que conduzam a formação para o pensamento crítico e reflexivo e para a cidadania. Portanto, a oficina sobre cosmografia e orientação geográfica realizada pelos bolsistas do PIBID Geografia UFSM, na Escola Municipal de Ensino Fundamental Junto ao CAIC Luizinho de Grandi, retomou a aprofundou um tema muito importante para a Geografia escolar e que precisa ser endocado na Educação Básica.

A oficina, portanto, motivou os estudantes quanto à retomada das temáticas que já haviam sido trabalhadas e auxiliou na construção e no avivamento dos conhecimentos sobre a temática. Os estudantes que ficaram eufóricos com as propostas desenvolvidas e demostraram muito interesse por todas as etapas da oficina. 


\section{CONCLUSÃO}

Com base nas atividades realizadas, concluiu-se que a oficina motivou os estudantes a relembrarem conhecimentos cosmográficos e cartográficos, isto é, orientação e localização geográfica trabalhados nas aulas de Geografia, bem como foi uma experiência enriquecedora aos bolsistas PIBID Geografia UFSM, especialmente, por ser a sua primeira inserção no espaço escolar. Essa inserção foi carregada de expectativas e de motivações para a construção de uma prática que estimulasse os estudantes a se interessarem pelos conhecimentos geográficos e que retomasse os saberes de modo prático e interativo. Assim, a proposta cumpriu o seu papel enquanto uma intervenção pedagógica que colabora com a aprendizagem dos estudantes da educação básica e, de mesmo modo, com a formação dos futuros docentes de Geografia.

Além disso, a proposta desenvolvida mostra que o projeto PIBID Geografia UFSM busca cumprir o seu papel social e reforça a aproximação das universidades da comunidade. Dessa forma, o PIBID reforça os vínculos entre universidade e escola e contribui para uma formação educacional de qualidade, pautada na reflexão e na ação por uma educação melhor e deve ser mantido e aprofundado como uma política pública essencial à formação de professores e à qualidade da educação básica. Ademais, a proposta desenvolvida retomou um importante tema da Geografia escolar, muitas vezes negligenciado pela disciplina, e que permite ampliar os horizontes de interpretação dos estudantes da educação básica, auxiliandoos em uma formação mais complexa e totalizando na compreensão do espaço vivido e do espaço ausente.

\section{REFERÊNCIAS}

ASCENÇÃO, V. O. R.; VALADÃO, R. C. Abordagem do conteúdo "relevo" na educação básica. In: CAVALCANTI, L. S. Temas da Geografia na escola básica. Campinas, SP: Papirus, 2013.

BATISTA, N. L. et al. S. O mapa de orientação como recurso didático na alfabetização cartográfica. XXVI Congresso Brasileiro de Cartografia, V Congresso Brasileiro de Geoprocessamento e XXV Exposicarta. Gramado, RS, 2014.

BATISTA, N. L. et al. Geografia e ensino I: uma experiência de integração universidadeescola na formação de professores de Geografia. Geographia meridionalis, v. 3, p. 364, 2017. 
BRASIL. Portaria GAB no 45, de 12 de março de 2018: Dispõe sobre a concessão de bolsas e o regime de colaboração no Programa de Residência Pedagógica e no Programa Institucional de Bolsa de Iniciação à Docência (PIBID). 2018. Disponível em: http://www.capes.gov.br/images/stories/download/ legislacao/01032018-portaria-n-38-de-2802-2018-residencia-pedagogica.pdf. Acessado em 11 de dezembro de 2018

DAMBROS, G. Por uma cartografia interativa: jogo digital para a alfabetização cartográfica no ensino fundamental. 122 páginas. (Dissertação de Mestrado). Programa de Pós-Graduação em Geografia. Santa Maria/RS: Universidade Federal de Santa Maria, 2014.

LIMA, E.F. (Org.). Sobrevivências no início de carreira. Brasília: Líber Livro Editora, 2006.

PASSINI, E. Y. Alfabetização cartográfica e a aprendizagem de geografia. São Paulo: Cortez, 2012.

RODRIGUES, T. T. A cosmografia geográfica como objeto de estudo para a compreensão das dinâmicas terrestres. Cadernos de Geografia (Coimbra), v. 1, p. 55-65, 2019.

SIMIELLI, M. E. R. Cartografia no ensino fundamental e médio. In: CARLOS, A. F. A. A. (Org.). Geografia em sala de aula. São Paulo: Contexto, 1999.

SOBREIRA, P. H. A. Cosmografia Geográfica: a astronomia no ensino de Geografia. (Tese de Doutorado). Programa de Pós-graduação em Geografia Física, Universidade de São Paulo - USP, 2005.

SOBREIRA, P. H. A. Releitura do conceito de cosmografia: a interface entre os estudos astronômicos e geográficos. GEOUSP Espaço e Tempo (Online), n. 1, v. 32, 2012, 161- 175.

TEIXEIRA, C. C; CASTROGIOVANNI, A. C. Orientação e lateralidade: uma proposta à luz da epistemologia genética. II Encontro de Práticas de Ensino de Geografia da Região Sul. Florianópolis: Anais eletrônicos UFSC, 2014. 